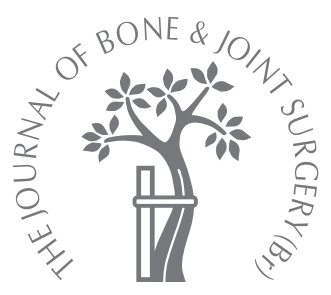

M. Fini,

M. Tschon,

M. Ronchetti,

F. Cavani,

G. Bianchi,

M. Mercuri,

M. Alberghini,

R. Cadossi

From the Rizzoli

Orthopaedic

Institute, Bologna,

Italy

M. Fini, MD, Researcher

= M. Tschon, BSc, Researcher

Laboratory of Preclinical and

Surgical Studies, Research

Institute Codivilla Putti

M. Alberghini, MD

Pathologist

Anatomy and Pathologica

Histology Unit

Rizzoli Orthopaedic Institute, via di Barbiano 1/10, 40136 Bologna Italy.

M. Ronchetti, BSc, Product Manager

n. Cadossi, PhD, President

and Director of Research and

Development

IGEA S.p.A via Parmenide 10

A, Carpi, 41012 Modena, Italy.

- F. Cavani, BSc, Researcher Department of Anatomy and Histology

University of Modena and

Reggio Emilia, via del Pozzo 71

41125 Modena, Italy.

In. Bianchi, MD, Orthopaedic Surgeon

M. Mercuri, MD, Orthopaedic

Surgeon

5th Ward of Oncologic

Orthopaedic-Trauma Surgery

Rizzoli Orthopaedic Institute, via

Pupilli 1, 40100 Bologna, Italy.

Correspondence should be sent to Dr M. Fini; e-mail:

milena.fini@ior.it

(C)2010 British Editorial Society of Bone and Joint Surgery doi:10.1302/0301-620X.92B11. $24664 \$ 2.00$

$J$ Bone Joint Surg $[\mathrm{Br}]$ 2010;92-B:1614-20.

Received 12 February 2010;

Accepted after revision 24 June 2010

\title{
Ablation of bone cells by electroporation
}

Short intense electrical pulses transiently increase the permeability of the cell membrane, an effect known as electroporation. This can be combined with antiblastic drugs for ablation of tumours of the skin and subcutaneous tissue. The aim of this study was to test the efficacy of electroporation when applied to bone and to understand whether the presence of mineralised trabeculae would affect the capability of the electric field to porate the membrane of bone cells.

Different levels of electrical field were applied to the femoral bone of rabbits. The field distribution and modelling were simulated by computer. Specimens of bone from treated and control rabbits were obtained for histology, histomorphometry and biomechanical testing.

After seven days, the area of ablation had increased in line with the number of pulses and/or with the amplitude of the electrical field applied. The osteogenic activity in the ablated area had recovered by $\mathbf{3 0}$ days. Biomechanical testing showed structural integrity of the bone at both times.

Electroporation using the appropriate combination of voltage and pulses induced ablation of bone cells without affecting the recovery of osteogenic activity. It can be an effective treatment in bone and when used in combination with drugs, an option for the treatment of metastases.

Short, intense electrical pulses cause a reversible permeability of the cell membrane as a consequence of reorientation of the polar molecules; a phenomenon known as electroporation (EP). ${ }^{1,2}$ The size and the number of pores formed depend on the amplitude of the electrical field and the duration of exposure or the number of pulses delivered. Very large electrical fields may induce the formation of large pores that do not reseal, resulting in cell lysis and death. ${ }^{3}$ Tissue EP is not associated with an increase in temperature or denaturation of protein. It exerts its effects selectively on cell membranes without damaging the extracellular matrix of the tissue, thereby allowing rapid and complete recovery of the affected area. ${ }^{4}$

During the application of electrical pulses, pore formation allows large molecules, such as DNA and RNA, to cross the cell membrane. Hydrophilic drugs with low permeability such as bleomycin and cisplatin can enter the cytosol, increasing their cytotoxicity, several thousandfold in the case of bleomycin. ${ }^{5}$ EP may severely impair the ability of the membrane to control the movement of calcium ions, allowing toxic concentrations to build up within the cell. EP of the cell membrane is used in clinical studies of gene delivery (electrogenetherapy), ${ }^{6}$ cytotoxic drug delivery (electrochemotherapy, ECT), ${ }^{7}$ and to induce cell lysis and death through the formation of large pores that do not reseal (irreversible electroporation). ${ }^{8}$

ECT has been shown to be effective in the treatment of tumours of the skin or subcutaneous tissue. The ESOPE trial ${ }^{9,10}$ has shown that, after a single short session of ECT, $74 \%$ of the treated tumour nodules had undergone a complete and $11 \%$ a partial response. No major negative side effects have been reported after ECT. Healthy tissue surrounding a metastasis is not affected and local recurrence of the tumour is rare. Research is in progress to extend its use to metastases in internal organs and to primary tumours.

EP combined with methotrexate has been used successfully in mice implanted with osteosarcoma cells. ${ }^{11}$ ECT might also be considered for the treatment of bone metastases, but to be effective, the electrical field applied must be distributed homogeneously across the entire tumour, so that all the cells undergo EP. ${ }^{12}$ 
This study was designed to evaluate how the presence of mineralised tissue would affect the distribution of the electrical field, to determine the electrical field sufficient to ablate all bone cells in the target area, to assess the recovery of osteogenic activity following cell ablation in the electroporated area and to evaluate the effect of EP on the mechanical competence of bone trabeculae.

\section{Materials and Methods}

Animal model. The study was performed according to Italian law on animal experimentation. The protocol was approved by the Ethical Committee of the Rizzoli Orthopaedic Institute, and by the Italian Ministry of Health. We used ten, five-month old, male New Zealand White rabbits with a mean weight of $2.5 \mathrm{~kg}$ (2.35 to 2.65$)$ housed under controlled conditions. General anaesthesia was induced with an intramuscular injection of $44 \mathrm{mg} / \mathrm{kg}$ ketamine (Ketavet 100; Farmaceutici Gellini SpA, Aprilia, Italy), $3 \mathrm{mg} / \mathrm{kg}$ xylazine (Rompun; Bayer AG, Leverkusen, Germany) and assisted ventilation $\left(\mathrm{O}_{2}: 1 \mathrm{l} / \mathrm{min}, \mathrm{N}_{2} \mathrm{O}: 0.4 \mathrm{l} / \mathrm{min}\right.$, isoflurane: $2.5 \%$ to $3 \%$ ). A $2 \mathrm{~cm}$ skin incision was made on the lateral surface of the distal femur on each side, and four stainless steel electrodes, $0.7 \mathrm{~mm}$ in diameter, were inserted into the trabecular bone in a square configuration at a distance of $4 \mathrm{~mm}$ by means of a positioning mask and a drilling device. In order to identify the conditions of EP required to ablate all the cells, increasing voltages and numbers of pulses were applied and the effects on bone compared to those in control animals who had insertion of electrodes only. The results obtained by applying 120 pulses at $1750 \mathrm{~V} / \mathrm{cm}$ were confirmed and subsequently used in two animals killed after 30 days to evaluate the long-term effects. After EP the electrodes were divided flush to the surface of the bone and the portions left inside were used as markers for subsequent analysis. The soft tissues were closed in layers. Antibiotics $(0.6 \mathrm{ml} / \mathrm{kg}$ flumexil, FATRO SpA, Bologna, Italy) were administered pre-operatively, immediately after surgery and at 24 hours after operation. Analgesics $(50 \mathrm{mg} / \mathrm{kg}$ farmolisina, Vatem SpA, Grosseto, Italy) were prescribed in the immediate post-operative period. The animals were killed at either seven or 30 days. In order to label bone formation, oxytetracycline $30 \mathrm{mg} / \mathrm{kg}$ (Terramicina 100, Pfizer Italia Srl, Latina, Italy) was injected intramuscularly on the second and third days after surgery in the animals killed after seven days, or after the 27th and 28th days in the animals killed at 30 days.

Delivery of the electrical pulse and modelling of the electrical field. Electrical pulses were generated by a custom-made Cliniporator (IGEA SpA, Carpi, Italy). The experimental conditions involved the use of increasing electrical fields of 1000 , 1300 and $1750 \mathrm{~V} / \mathrm{cm}$ with 50 to 240 pulses lasting $100 \mu$ s delivered at $4 \mathrm{~Hz}$.

Ten animals were treated with electropation in order to have the following conditions: at seven days EP at $1000 \mathrm{~V} / \mathrm{cm}$ at 120 , 180 and 240 pulses; $1300 \mathrm{~V} / \mathrm{cm}$ at 120 and 180 pulses and $1750 \mathrm{~V} / \mathrm{cm}$ at 50, 80 and 120 pulses; at 30 days 120 pulses at
$1750 \mathrm{~V} / \mathrm{cm}$. The effect of bone drilling only was investigated in the right femurs of four animals at seven days and of two animals at 30 days.

The four electrodes were connected by couples and in each individual experiment the same number of pulses was used. The distribution of the electrical field and the absorbed dose (AD) in the bone tissue were calculated using computer software (COMSOL Multiphysics, Burlington, Massachusetts). For the calculations, conductivity values of $4.032 \mathrm{e} 6[\mathrm{~S} / \mathrm{m}]$ and $0.02[\mathrm{~S} / \mathrm{m}]$ were used for the electrodes and bone, respectively. ${ }^{13}$ The AD $(\mathrm{J} / \mathrm{kg})$ was calculated using the following formula:

$$
A D=\sigma \frac{E^{2}}{\rho} \tau
$$

where $\sigma$ is the material conductivity, $\mathrm{E}$ the local electrical field, $\rho$ the material density and $\tau$ the total duration of the applied pulses. ${ }^{14}$

For the conductivity of bone we used the values recorded in Miklavčič et $\mathrm{al}^{13}{ }^{13}$ which are applicable to bone before delivery of the pulses, although tissue conductivity augments following EP of the cell membrane.

According to modelling of the electrical field, the centre of the geometric square defined by the four electrodes experiences the lowest values of $\mathrm{AD}$ considered to be the threshold for tissue ablation.

Histology and histomorphometry. Distal femurs were excised and cut in lateral and medial specimens with an Exact 300 band system (Exact Apparatebau GmbH, Nordestedt, Germany). The lateral specimens were processed undecalcified. The samples were fixed in $4 \%$ paraformaldehyde for 48 hours, dehydrated in a graded series of alcohols and embedded in polymethylmethacrylate (Merck, Schuchardt, Hohenbrunn, Germany). The blocks were then sectioned along a plane parallel to the diaphyseal axis using a Leica 1600 diamond saw microtome (Leica SpA, Milan, Italy). Tetracycline emission by new bone formation in the unstained sections was observed under fluorescence with a light microscope (Olympus BX41, Melville) $(\lambda=410 \mathrm{~nm})$. The lack of emission under fluorescence is due to the loss of new deposition of mineral by the osteoblasts and indicates local ablation of osteoblasts. The ablated area was quantified by measuring the distance at which the tetracycline-labelled bone was observed from each of the four electrode surfaces. Semi-automatic measurement was performed with Q-Win Image Analysis Software (Leica Imaging Systems, Cambridge, United Kingdom) on three sections glued to a methylmethacrylate support and cut further to a thickness of $5 \mu \mathrm{m}$ with a microtome, (1150/Autocut, Reichert-Jung, Nussbloch, Germany) and stained with toluidine blue and fast green.

The medial parts of the distal femurs were fixed in $10 \%$ neutral buffered formalin for 24 hours, decalcified in a for$\mathrm{mic} /$ nitric acid solution for 36 to 40 hours, dehydrated and processed into wax. Sections $4 \mu \mathrm{m}$ thick were stained with haematoxylin-eosin. 


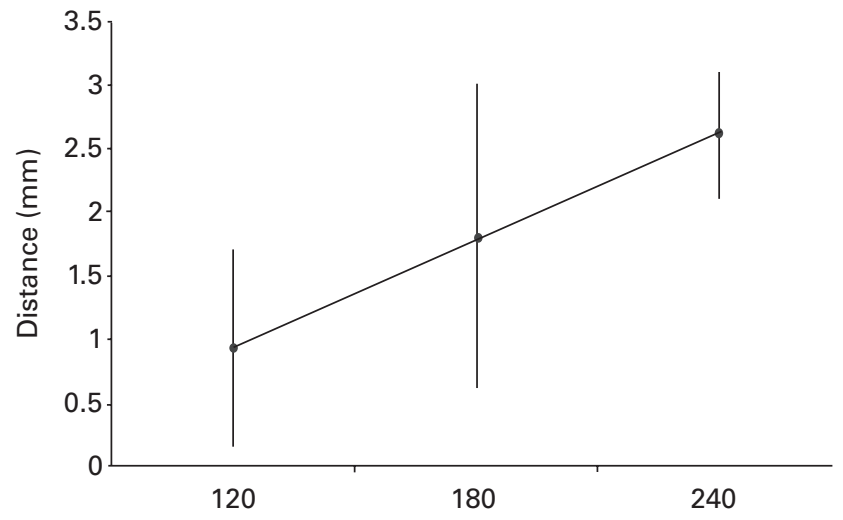

Number of pulses

Fig. 1

Extent of ablation of bone fluorescence from the electrode $(\mathrm{mm})$ versus the number of pulses applied at $1000 \mathrm{~V} / \mathrm{cm}$.

Bone microhardness. The microhardness (HV) of bone was evaluated by a Vickers indentation using a microdurimeter Durimet (Leitz, Wetzlar, Germany) on specimens embedded in methylmethacrylate. Measurements were taken on bone trabeculae within the electrodes in treated specimens and in the corresponding areas of the control animals. Under a load of $25 \mathrm{~g}$ for each specimen, 22 imprints were performed, and the length of their diagonals measured by a screw micrometric eye-piece at a magnification of $40 \times$. The HV number was calculated by the formula $\mathrm{HV}=1854.4 \times \mathrm{L} / \mathrm{d}^{2}$, where $\mathrm{L}$ is the load in grams and $\mathrm{d}$ is the mean length of the diagonals of the imprint measured in micrometres $(\mu \mathrm{m})$. It is expressed in $\mathrm{kg} / \mathrm{mm}^{2}$.

Statistical methods. Statistical analysis was performed using the SPSS v.12.1 software (SPSS Inc., Chicago, Illinois). Data distribution was verified by the KolmogorovSmirnov test before performing Student's $t$-test. Bone HV was reported as a mean and SD, $\mathrm{p}<0.05$ was considered statistically significant.

\section{Results}

All animals survived the procedures without complication. Tetracycline labelling was observed in the control bone seven days after insertion of the electrodes. Apposition of new bone was evident in the trabecular bone around and within the electrodes, thereby demonstrating that the insertion did not affect mineral apposition and the viability of the bone tissue. When a $1000 \mathrm{~V} / \mathrm{cm}$ electrical field was applied to their electrodes, 120, 180 and 240 pulses respectively, were delivered. Histomorphometry showed that the distance from the surface of the electrode and the fluorescent-labelled new bone increased linearly with the number of pulses (Fig. 1). At 240 pulses no tetracycline labelling remained among the electrodes.

Histological examination showed osteoblasts at the rims of trabeculae and less intense cartilage staining when
120 pulses were used. In bone tissue exposed to 240 pulses, no osteoblasts were present on the trabeculae among the electrodes and the cartilage was unstained.

When the electrical field was increased to $1300 \mathrm{~V} / \mathrm{cm}$ and EP was performed with 120 and 180 pulses, the fluorescence staining of bone among the electrodes was still present when 120 pulses were delivered, but in the sample treated with 180 pulses no tetracycline fluorescence was observed and the histology showed complete ablation of osteoblasts from the trabeculae. The cartilage did not stain, and chondrocytes appeared pyknotic.

When the electrical field was increased to $1750 \mathrm{~V} / \mathrm{cm}$, 120 pulses were sufficient to prevent tetracycline labelling among the electrodes (Fig. 2a). The histology showed ablation of osteoblasts from the trabeculae, and the osteocyte lacunae were occupied by pyknotic nuclei (Fig. 2b). Cartilage did not stain on lowering the number of pulses to 80 and 50, the tissue damage decreased and the ablated area had lower values. At 50 pulses cartilage staining was largely maintained, tetracycline labelling was visible among the electrodes (Fig. 2c), and bone cells were still present on trabeculae (Fig. 2d). An increase in size of the ablated area was also observed according to the number of pulses.

When the number of pulses was constant at 120 , the ablated area enlarged as the voltage increased (Fig. 3). Around each electrode, the area of ablation increased with the number of pulses delivered and/or if the amplitude of the electrical field increased. We considered the combined effect of the number of pulses and voltage applied on the extent of ablation as AD in the tissue (Fig. 4). In the different experimental conditions, ablation of bone tissue was reached when the $\mathrm{AD}$ values were $>3500 \mathrm{~J} / \mathrm{kg}$ (Fig. 5).

The EP protocol of $1750 \mathrm{~V} / \mathrm{cm}$ and 120 pulses was used in animals killed on day 30. Tetracycline labelling showed marked deposition of new bone among the electrodes, although there was no activity around their surfaces (Fig. 6a). The osteogenetic activity was moving from peripheral bone towards the central area defined by electrodes. Histological analysis showed a large number of mesenchymal cells arising from bone marrow among the bone trabeculae. Marked modelling activity was present. The osteocyte lacunae in the middle of old trabeculae appeared to be empty. Cartilage did not stain and no repair activity was observed (Fig. 6b).

$\mathrm{HV}$ measurements of trabeculae were performed in the controls and in bone electroporated with $1750 \mathrm{~V} / \mathrm{cm}$ and 120 pulses. The mean HV values $\left(\mathrm{kg} / \mathrm{mm}^{2}\right)$ did not change significantly: controls 55.5 (SD 5.4), p > 0.05; EP bone at seven days: 51.3 (SD 7.7), $\mathrm{p}>0.05$; EP bone at 30 days 50.2 (SD 6.2), $\mathrm{p}>0.05$.

\section{Discussion}

We investigated whether and to what extent the structure and non-homogeneity of bone tissue could interfere with and limit the use of EP for cell ablation. EP and bleomycin have already been used successfully in a patient suffering 


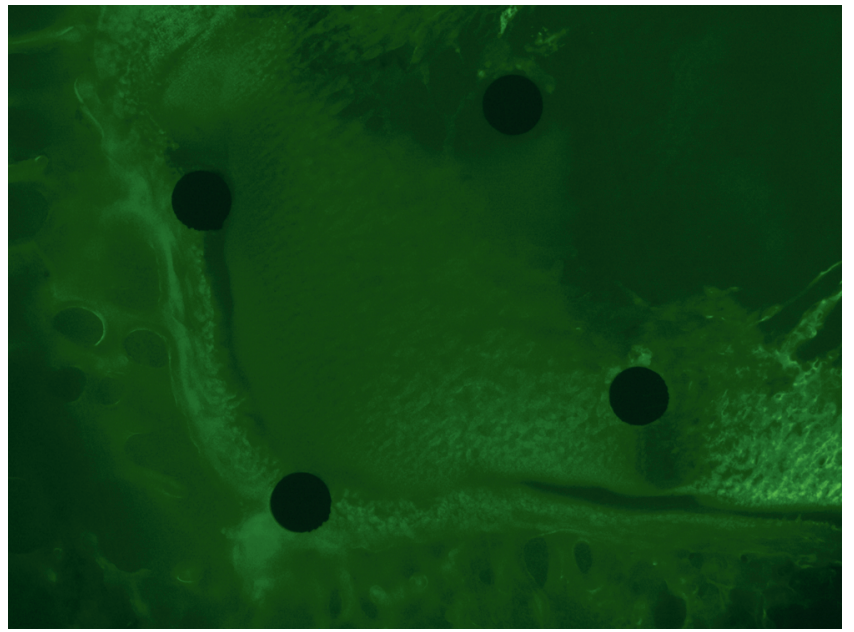

Fig. 2a

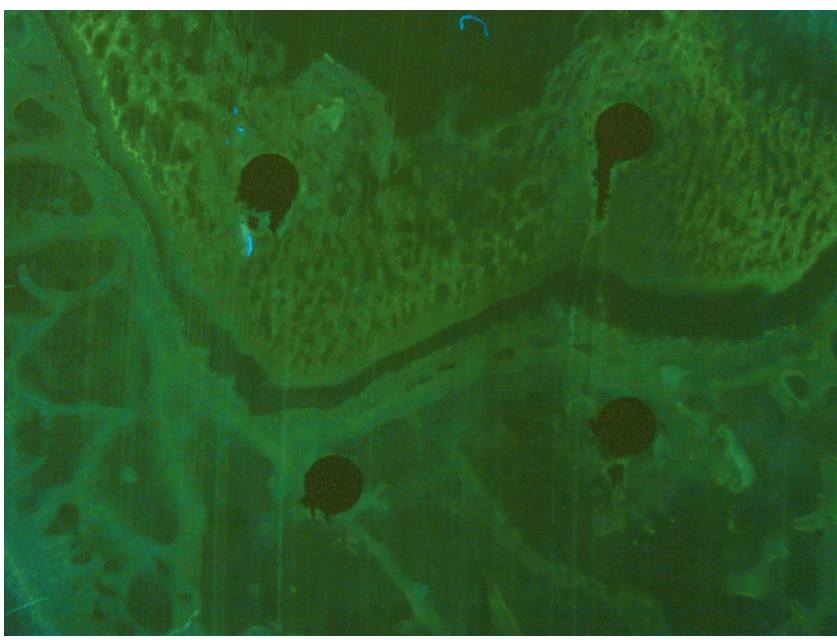

Fig. 2c

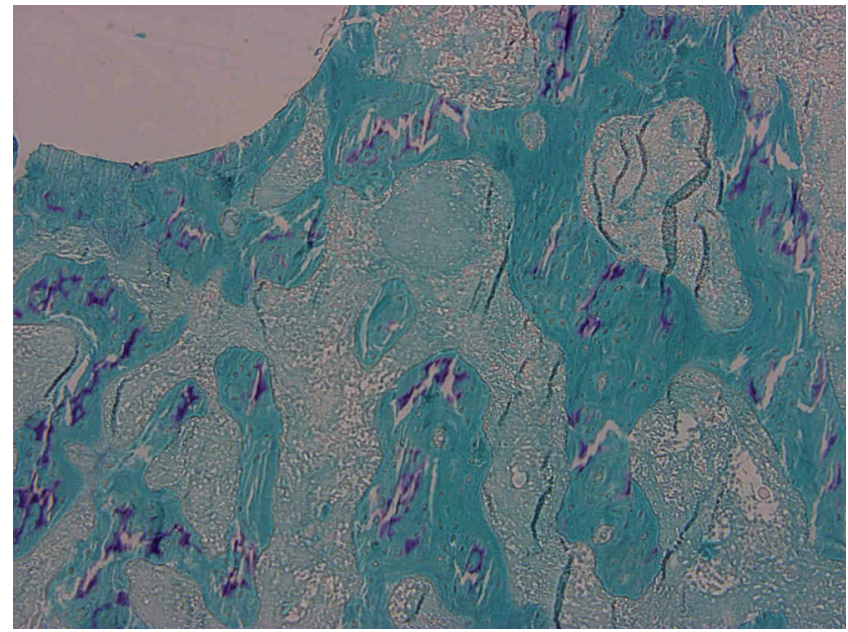

Fig. $2 b$

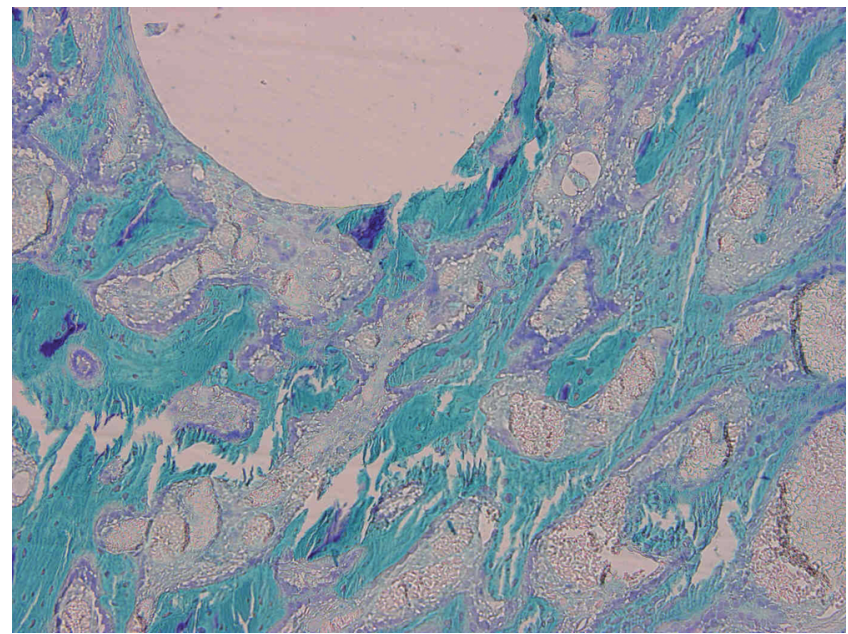

Fig. $2 d$

Electroporation of bone tissue at $1750 \mathrm{~V} / \mathrm{cm}$ with different number of pulses: $120(\mathrm{a}, \mathrm{b})$ and 50 (c, d) pulses: unstained sections (a, c: $1.25 \times$ magnification), toluidine blue and fast green-stained sections (b, d: 10x magnification). Figure $2 a-$ Tetracycline labelling was completely prevented by 120 pulses. Figure $2 b-$ osteoblasts were not present on bone trabeculae. Figure $2 c-50$ pulses did not prevent tetracycline labelling. Figure $2 d-$ viable bone cells are present among electrodes.

from chondrosarcoma. ${ }^{15}$ Nevertheless, to our knowledge, no specific preclinical investigations on the effectiveness of electrical fields to induce permeability of the cell membrane in bone tissue have been conducted. We have shown that the mineralised tissue does not prevent EP of cells among trabeculae, osteoblasts and bone marrow cells, and osteocytes within trabeculae.

EP was tested in the distal femur, an area of high metabolic activity owing to the presence of the articular cartilage, to highlight its effect on osteoblast activity by evaluating bone fluorescence emission after tetracycline labelling.

Several protocols for EP have been tested by changing the amplitude of the electrical field and the number of pulses delivered. We have shown that the distance from the surface of the electrode where cell ablation was observed increased with an increase in the number of pulses and the strength of the field applied.

By raising the number of pulses, complete ablation of bone cells among the electrodes was achieved for all levels of the electrical field at 80, 180 and 240 pulses for 1750 , 1300 and $1000 \mathrm{~V} / \mathrm{cm}$, respectively. We showed that when the amplitude of the field and the number of pulses are combined to calculate the tissue $\mathrm{AD}(\mathrm{J} / \mathrm{kg})$, its value can be related to the efficiency of ablation by EP. A similar finding was described by Ibey et $\mathrm{al}^{14}$ when investigating the efficacy of ultra-short pulses in vitro. We identified the AD threshold $(3500 \mathrm{~J} / \mathrm{kg}$ ) above which cell damage becomes irreversible and leads to cell death. As the energy is delivered at low frequency $(4 \mathrm{~Hz})$ by intense but short electrical pulses of $100 \mu \mathrm{s}$, the increase in temperature at the surface of the electrode after each pulse is limited and dissipates com- 


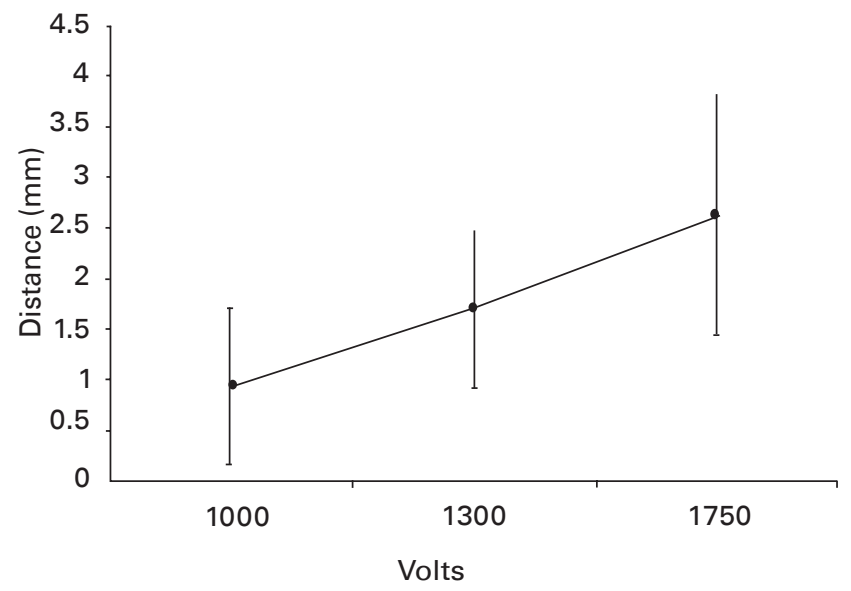

Fig. 3

Extent of ablation of bone fluorescence from electrode surfaces (in $\mathrm{mm}$ ) versus the voltage applied at 120 pulses.

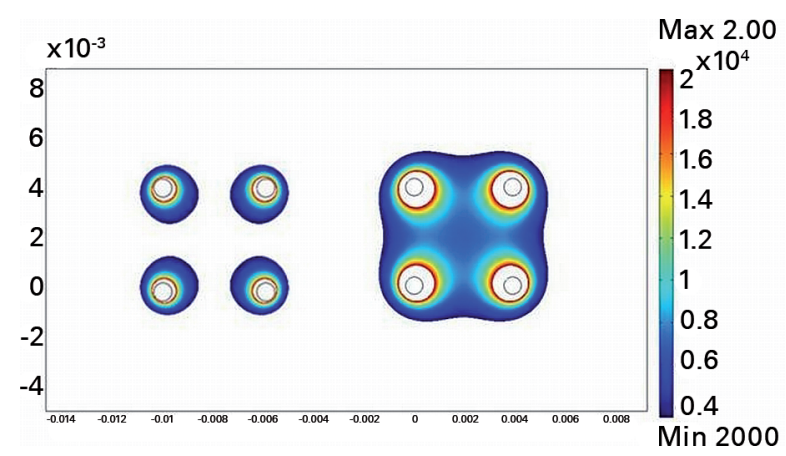

Fig. 4

Absorbed dose (AD) in the tissue when $1750 \mathrm{~V} / \mathrm{cm}$ are applied to the electrodes using: left, 50 pulses, and right 120 pulses. The dark blue represents the minimum $A D$ value $(3500 \mathrm{~J} / \mathrm{kg})$ required for tissue ablation.

pletely before the following pulse; this prevents an increase in tissue temperature and protein denaturation. . $^{3,4}$

In animals killed on day seven, oxytetracycline was injected on the second and third days after surgery in order to monitor blockage of bone deposition immediately after EP; in animals killed on day 30 oxytetracycline was injected on days 27 and 28 to assess the activity of osteoblasts when the animals were killed. The complete ablation produced by EP is generally quick. Even by the second day after the procedure, the administered tetracycline is not incorporated and bone is not labelled, indicating the immediate functional block of osteoblast activity. Histology on the seventh day showed pyknotic osteocytes within the bone trabeculae and the almost complete absence of osteoblasts. The few cells observed on the trabecular surface had an irregular shape, with large vacuoli in the cytoplasm, and osteocytes undergo apoptosis, as revealed by positive staining for $\mathrm{Bcl}$ 2. The growth cartilage did not stain and few pyknotic chondrocytes were seen.

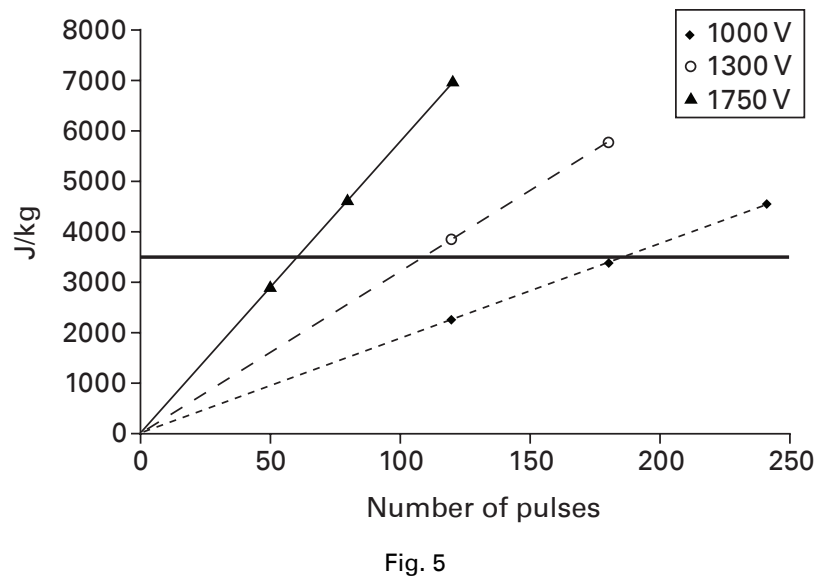

Absorbed dose in bone tissue as the number of pulses increased for the different electrical field values applied. The black horizontal line indicates values above which the whole bone area confined among the electrodes is ablated.

It has been proposed that when high electrical fields are employed the pores created by EP in the membrane cannot be resealed, and then cause cell death by cell lysis. ${ }^{3}$ However, we do not consider that this mechanism can fully explain our results. We observed apoptotic cells seven days after EP, when large fields were employed which were supposed to create large irreversible pores. We also showed that with the electrical field $(1000 \mathrm{~V} / \mathrm{cm})$ routinely used for ECT, it is still possible to obtain complete cell ablation if a large number of pulses are delivered, thereby increasing the duration of exposure. Under these conditions we consider that cell death stems from the prolonged impairment of cell membrane function, leading to loss of cell homoeostasis and irreversible intracellular damage. If the local electrical field values are sufficient $(>250 \mathrm{~V})$ to induce pore formation, ${ }^{13}$ loss of membrane function occurs as a result of increasing the number of pulses. In particular, $\mathrm{Ca}^{2+}$ compartmentalisation produces sustained severe damage to the structure and respiratory chain of the cytoplasm, a condition from which the cell is unable to recover. The mechanism of cell ablation is not necessarily due to loss of the integrity of the cell membrane, but rather to the severity and duration of the damage suffered by vital cell functions.

By 30 days after EP, intense osteogeneic activity among the electrodes was visible with tetracycline labelling. There were new trabeculae and the presence of vessels. Reparative activity was not present immediately around the electrodes, where the highest $\mathrm{AD}$ values had been experienced.

EP was not associated with changes in the $\mathrm{HV}$ of the bone trabeculae. Boivin et $\mathrm{al}^{16}$ showed that bone $\mathrm{HV}$ as measured by Vickers indentation, is correlated to Young's modulus and the degree of mineralisation of the bone trabeculae.

Our results show that EP can be effectively used to ablate cells in bone, provided that the proper combination of 


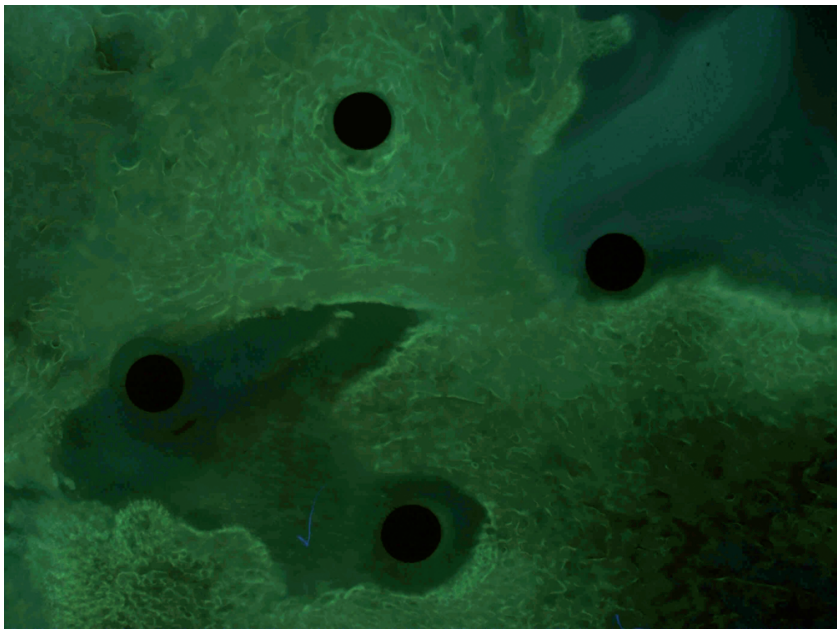

Fig. 6a

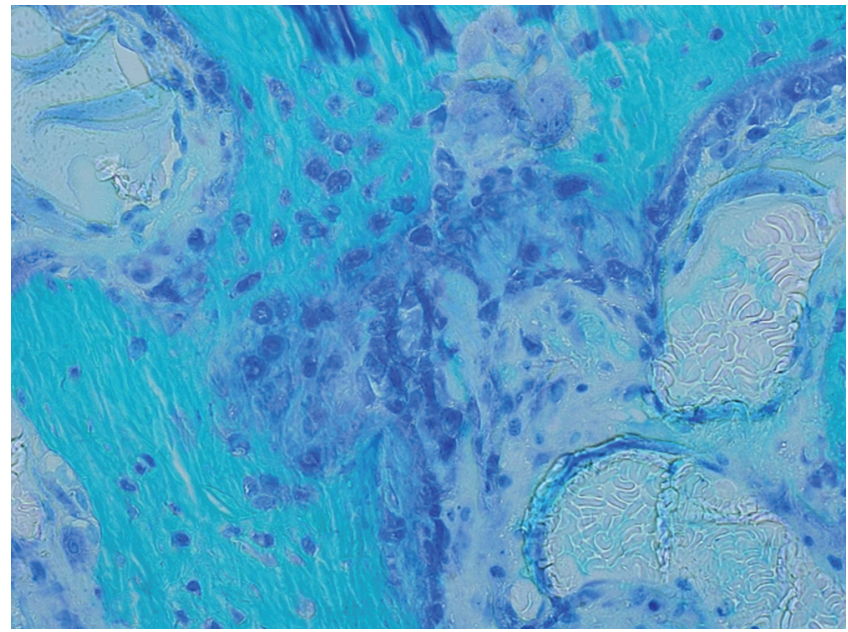

Fig. $6 \mathrm{~b}$

Histology of bone tissue of animals killed 30 days after electroporation treatment. Figure $6 a-$ new bone formation evidenced by tetracycline labelling (unstained sections, 1.25x magnification). Figure $6 \mathrm{~b}$ - intense osteogenic activity is present within trabecular bone and on its surface (toluidine blue and fast green staining, $20 \times$ magnification).

amplitude of the electrical field and the number of pulses is used. Mathematical modelling allows the calculation of AD maps in the tissue, and the treatment protocols needed to ensure that the whole area of interest is ablated. In our experiments we used a square geometry for electrodes. However, electrodes inserted into the target area can be adapted to any geometry of the tissue to be ablated. The available technology allows the application of an electrical field of up to $3000 \mathrm{~V}$, so separation of the electrodes can be increased by up to $3 \mathrm{~cm}$ and their number increased to ascertain complete EP of large volumes of tissue. Electrical fields can be calculated and customised to a complex threedimensional geometry so that effective energy and frequency can be delivered.

The main limitations of the study are linked to the number of animals used and to the method of assessing the functional blockage of bone formation and cell ablation from trabeculae, mainly based on histology. Nevertheless, the study shows that EP can be used in the context of a mineralised tissue, that bone trabeculae do not prevent homogeneous cell ablation, and provides the knowledge necessary to extend the use of the technology to the study of ablation of bone metastases using EP.

Bone metastases are common disabling complications in patients suffering from cancer. Available treatments include radiotherapy, thermal and cryoablation, resection and the application of bone cement to fill osteolytic areas. ${ }^{17}$

The surgical removal or the ablation of a metastasis has to be carefully considered because safe lesional margins cannot always be achieved owing to the presence of structures that must be preserved. This is particularly relevant for metastases to vertebral bodies, especially when the posterior lamina is involved, because of its proximity to the spinal cord.
These concerns are present when techniques such as radiofrequency thermal ablation cause dissipation of heat and damage to protein and the connective and vascular structures. This technique also leaves the trabecular structure not mechanically competent. Cryosurgery is particularly complex and has several side effects. ${ }^{18}$

EP may be a viable alternative, as the tissue matrix, protein and collagen are preserved. ${ }^{19}$ However, when EP is used alone to obtain cell ablation, the amount of energy delivered is relatively high, which may trigger an inflammatory reaction. If EP is used in combination with drugs, the electrical field does not need to exceed $1000 \mathrm{~V} / \mathrm{cm}$ and the number of pulses delivered can be limited to eight between each electrode couple. ${ }^{20}$ With ECT the combined effect of EP and cytotoxic drugs can be particularly effective, as it allows large volumes of tumour to be treated. The drugs enter the cell at values of the electrical field sufficient to affect the permeability of the membrane reversibly. EP increases bleomycin cytotoxicity by 10000 times. $^{21}$

Clinical experience with the use of ECT for the treatment of cutaneous and subcutaneous metastases has shown a $74 \%$ complete response of treated nodules. ${ }^{9}$ Extending the use of ECT to bone might bring a marked benefit to patients, considering that the treatment is completed in a few milliseconds after positioning of the electrode, and the lack of side effects. ${ }^{22}$

We have shown that EP can be performed effectively in bone. This allows the use of ECT in the treatment of bone metastases in humans, a study that is currently being conducted.

\section{Listen live}

Listen to the abstract of this article at www.jbjs.org.uk/interactive/audio 
This work was partially supported by Carisbo Foundation Project n.1496 entitled 'Tecniche innovative di ablazione tumorale mediante associazione di elettroporazione e chemioterapici' and by Project. n. A20/1837/00/X06, 'Studio e sviluppo di un'innovativa Piattaforma Tecnologica per Elettropoazione (PTE) per la terapia dei tumori profondi' of Ministero dello Sviluppo Economico.

The author or one or more of the authors have received or will receive benefits for personal or professional use from a commercial party related directly or indirectly to the subject of this article.

\section{References}

1. Neumann E, Rosenheck K. Permeability changes induced by electric impulses in vesicular membranes. J Membr Biol 1972;10:279-90.

2. Neumann E, Schaefer-Ridder M, Wang Y, Hofschneider PH. Gene transfer into mouse lyoma cells by electroporation in high electric fields. EMBO J 1982;1:841-5.

3. Davalos RV, Mir IL, Rubinsky B. Tissue ablation with irreversible electroporation. Ann Biomed Eng 2005;33:223-31.

4. Esser AT, Smith KC, Gowrishankar TR, Weaver JC. Towards solid tumour treatment by irreversible electroporation: intrinsic redistribution of fields and currents in tissue. Technol Cancer Res Treat 2007;6:261-74.

5. Mir LM. Therapeutic prespectives of in vivo cell electropermeabilisation. Bioelectrochemistry 2001;53:1-10.

6. Gehl J. Electroporation: theory and methods, perspectives for drug delivery, gene therapy and research. Acta Physiol Scand 2003;177:437-47.

7. Mir LM, Belehradek M, Domenge C, et al. Electrochemotherapy, a new antitumor treatment: first clinical trial. C R Acad Sci III 1991;313:613-18 (in French).

8. Rubinsky B, Onik G, Mikus P. Irreversible electroporation: a new ablation modality - clinical implications. Technol Cancer Res Treat 2007;6:37-48.

9. Marty M, Sersa G, Garbay JR, et al. Electrochemotherapy: an easy, highly effective and safe treatment of cutaneous and subcutaneous metastases: results of ESOPE (European Standard Operating Procedures of Electrochemotherapy) study. Eur J Cancer Supp/ 2006;4:3-13.

10. Mir LM, Gehl J, Sersa G, et al. Standard operating procedures of the electrochemotherapy: instructions for the use of bleomycin or cisplatin administered either systematically or locally and electric pulses delivered by the Cliniporator ${ }^{\mathrm{TM}}$ by means of invasive or non-invasive electrodes. Eur J Cancer Supp/ 2006;4:14-25.

11. Isobe K, Shimizu T, Nikaido T, Takaoka K. LoW-voltage electrochemotherapy with low-dose methotrexate enhances survival in mice with osteosarcoma. Clin Orthop 2004;426:226-31.

12. Corovic S, Pavlin M, Miklavcic D. Analytical and numerical quantification and comparison of the local electric field in the tissue for different electrode configurations. Biomed Eng Online 2007;6:37.

13. Miklavčič D, Pavšelj N, Hart FX. Electric properties of tissues. In: Wiley encyclopedia of biomedical engineering. New York: John Wiley and Sons, 2006:357889 .

14. Ibey BL, Xiao S, Schoenbach KH, Murphy MR, Pakhomov AG. Plasma membrane permeabilization by 60- and 600-ns electric pulses is determined by the absorbed dose. Bioelectromagnetics 2009;30:92-9.

15. Shimizu T, Nikaido T, Gomyo H, et al. Electrochemotherapy for digital chondrosarcoma. J Orthop Sci 2003;8:248-51.

16. Boivin G, Bala Y, Doublier A, et al. The role of mineralization and organic matrix in the microhardness of bone tissue from controls and osteoporotic patients. Bone 2008;43:532-8.

17. Callstrom MR, Charboneau JW. Image-guided palliation of painful metastases using percutaneous ablation. Tech Vasc Interv Radio/ 2007;10:120-31.

18. Capanna R, De Biase P, Sensi L. Minimally invasive techniques for treatment of metastatic cancer. Orthopade 2009;38:343-7 (in German).

19. Maor E, Ivorra A, Leor J, Rubinsky B. The effect of irreversible electroporation on blood vessels. Technol Cancer Res Treat 2007;6:307-12.

20. Sersa G, Miklavcic D, Cemazar M, et al. Electrochemotherapy in treatment of tumours. Eur J Surg Oncol 2008;34:232-40.

21. Mir LM, Orlowski S, Belehradek J Jr, Paoletti C. Electrochemotherapy potentiation of antitumour effect of bleomycin by local electric pulses. Eur $J$ Cancer 1991;27:68-72

22. Campana LG, Mocellin S, Basso M, et al. Bleomycin-based electrochemotherapy: clinical outcome from a single institution's experience with 52 patients. Ann Surg Oncol 2009;16:191-9. 